\title{
The Influence of Modified Open-Plan Preschool Spaces on Cognitive School Readiness in Malaysia
}

\author{
Mariam Felani Shaari ${ }^{1}$, Yazid Zaiki ${ }^{2}$, Sabarinah Sheikh Ahmad ${ }^{1}$, Izaham Shah Ismail ${ }^{3}$ \\ ${ }^{1}$ Centre of Studies for Architecture, Faculty of Architecture, Planning and Surveying, Universiti Teknologi MARA, Malaysia \\ 2 Institute of Pharmacology, National Yang-Ming University, Taiwan \\ ${ }^{3}$ Centre of Postgraduate Studies, Faculty of Education, Universiti Teknologi MARA, Malaysia \\ mariamfelani@uitm.edu.my, yazidzaiki@ym.edu.tw, sabar643@uitm.edu.my, izaha740@uitm.edu.my \\ Tel: +60125060875
}

\begin{abstract}
Modified open-planning to define children's spaces is important in preschool design. Cognitive school readiness (SR) is an objective of Malaysian preschools. This study investigates the correlation between modified open-plan spaces and cognitive SR in Malaysian preschools. A prospective cohort study involving 378 children at 18 Malaysian Ministry of Education (MOE) preschools was conducted. Compared to other preschool physical aspects (size, scale, circulation, facilities, indoor environment quality, safety, home bases, activity areas, and play yards), the quality of modified open-plan spaces showed the strongest correlation with children's cognitive SR (Pearson's $r=0.658, p=0.000$ ). Findings are hoped to promote better preschool designs.
\end{abstract}

Keywords: Modified open-plan, preschool design, children education, school readiness

eISSN: 2398-4287C 2020. The Authors. Published for AMER ABRA cE-Bs by e-International Publishing House, Ltd., UK. This is an open access article under the CC BYNC-ND license (http://creativecommons.org/licenses/by-nc-nd/4.0/). Peer-review under responsibility of AMER (Association of Malaysian Environment-Behaviour Researchers), ABRA (Association of Behavioural Researchers on Asians) and cE-Bs (Centre for Environment-Behaviour Studies), Faculty of Architecture, Planning \& Surveying, Universiti Teknologi MARA, Malaysia. DOI: https://doi.org/10.21834/ebpj.v5i15.2466.

\subsection{Introduction}

Since Malaysia first participated in international children benchmarks, PISA (Programme for International Student Assessment) assessments continue to flag a worrying trend - Malaysian children remain behind in problem-solving and critical thinking skills compared to global peers (MOE, 2020; OECD, 2018). The Malaysian Education Blueprint 2013 - 2025 (MEB 2025) was introduced to address this, along with other objectives. Cognitive-oriented curriculum and higher-order thinking skills (HOT) were incorporated into the education system to improve the grasp of cognitive abilities.

To ensure children are equipped with the skills to partake in such a curriculum, public preschools in Malaysia were tasked to nurture children to be cognitively ready for primary school (MOE, 2020). This promotion of cognitive school readiness (SR) is important as it helps establish crucial developmental foundations needed for children to acquire more complex skills as they progress. Studies have established that children with high cognitive SR are better equipped to perform better in life (Blair \& Raver, 2015; Davies et al., 2020). But for preschools to maximise this, classroom environments must be conducive to accommodate such pedagogy. Activity spaces should be designed with children's learning behaviour in mind (Abbas et al., 2016; Dayaratne, 2016).

Modified open-plan spaces offer the flexibility to accommodate various preschool activities. By having spaces that are partially enclosed to shield children from distractions but provide ample room for supervised learning, children's learning through dramatic and

eISSN: 2398-4287C 2020. The Authors. Published for AMER ABRA cE-Bs by e-International Publishing House, Ltd., UK. This is an open access article under the CC BYNC-ND license (http://creativecommons.org/licenses/by-nc-nd/4.0/). Peer-review under responsibility of AMER (Association of Malaysian Environment-Behaviour Researchers), ABRA (Association of Behavioural Researchers on Asians) and cE-Bs (Centre for Environment-Behaviour Studies), Faculty of Architecture, Planning \& Surveying, Universiti Teknologi MARA, Malaysia.

DOI: https://doi.org/10.21834/ebpj.v5i15.2466. 
pretend play can flourish (Moore, 2012). Moreover, such classroom settings reinforce classical and operant conditioning in children to boost their acquisition of cognitive abilities.

Despite many studies advocating such planning in preschools, the importance of modified open-plan spaces remains overlooked in Malaysia - most public preschools adopt open-planned classrooms with little effort to define space for specific activities (quiet, messy and physical) (Abbas, 2016; Mohidin et al., 2015). Occasionally, some elements of modified open-plan spaces are seen in public Malaysian preschools, but their use is often minimal (Figure 1). A lack of awareness on the importance of spatial planning in preschool design is suspected, as evident in the lack of emphasis seen in The Malaysian Education Blueprint 2013 - 2025 (MEB 2025) (MOE, 2020; Shaari et al., 2020b).

\subsection{Literature Review}

When designing children spaces, appropriate placement of partial enclosures or furniture can be done to define or 'modify' an otherwise open classroom (Figure 1). Recent studies continue to support the fact that open plan spaces are useful as they are spacious, but they also pose an inherent problem for preschool - open planned spaces are overwhelming and confusing for children and could be detrimental for spatial orientation (Oseland, 2018). Hence, modified open-plan spaces are effective to harness the benefits of both open and closed planning. In preschools, they are especially useful to create cosy spaces that reinforce learning but are not too big to overwhelm the child (Moore, 2012). Moreover, crucial aspects for cognitive development namely acoustic clarity and speech recognition among children are greatly affected by classroom planning through intrusive and background noise (Mealings et al., 2015).

Thus, given the dynamic nature of preschool learning activities, classroom environments must also be equally adept to accommodate these contrasting daily activities. Indeed, the extensive work done by Moore (2012) and others (Dayaratne, 2016) advocate the importance of having pockets of home-like spaces in classrooms. As play-based learning is crucial in preschool-aged children, environments that encourage children's explorative behaviour and promote unobstructed teacher-children interaction while allowing easy access to other activity areas are important - a unique advantage of adopting modified open-planning (Mickelson, 2019).
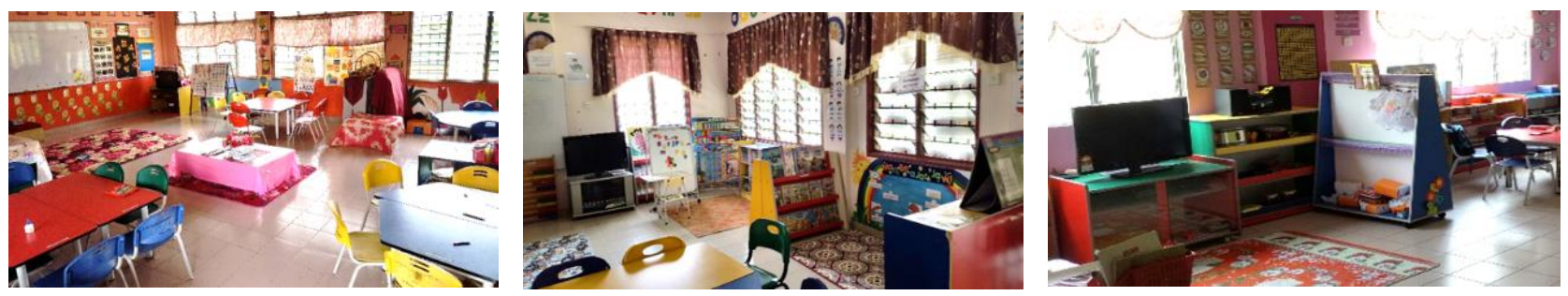

Fig 1. Examples of open-plan (left) and modified open-plan preschool spaces (centre, right) in Malaysian MOE preschools (Source: Author)

The importance of cognitive development and subsequent cognitive SR in early childhood is established - the UNICEF explicitly advocates cognitive SR as a means to ensure a brighter future for children, especially in poor communities where access to high-quality education is limited. For preschool children, cognitive SR is reflected in various aspects of cognitive abilities namely reading, counting, colour recognition, comparative, and problem-solving skills (UNICEF, 2017). Specifically, in Malaysia and under MEB 2025, such skills comprise the basis of many aspects of preschool curriculum and thus are crucial milestones for preschoolers to achieve before they enter primary school (MOE, 2020). Moreover, as studies show, cognitive proficiencies also contribute to other aspects of development namely physical, motor, and emotional capabilities - further highlighting its importance (Raghubar \& Barnes, 2017; Bracken, 2007).

Piaget's Theory of Cognitive Development and the constructivist-interactionist approach to human development have long been popular references in children's developmental psychology and is often adopted in Western institutions to promote appropriate preschool designs to maximize cognitive development (Schultz \& Schultz, 2016). Based on Piaget's theory, the preschool physical environment (PPE) is a vital source of stimuli to encourage positive cognitive development (Moore, 2012). Hence, many aspects of PPE design namely size, image, circulation, shared facilities, safety, spatial planning of activity spaces, and location have the potential to influence the effectiveness of pedagogy on children.

Preschool buildings must be designed to reinforce positive learning experiences and minimize negative ones for proper cognitive development to take place. Without properly-designed PPE, other elements of the preschool system cannot function properly. As an example, a well-devised curriculum cannot be delivered correctly without a conducive classroom, and so forth.

It was previously reported that the quality of PPE design was positively associated with children's cognitive SR (Shaari et al., 2020a). However, the reasons to explain this relationship remains to be explored. Thus, the current study aims to investigate the relationship between the quality of modified open-plan spaces and cognitive SR among Malaysian preschoolers. Specifically, our objective is to establish the degree of correlation between these two aspects in the hope to shed more light into understanding children's cognitive development in the Malaysian preschool context.

\subsection{Method}

\subsection{Aims and Objectives}


The aim is to investigate the relationship between the quality of modified open-plan spaces and cognitive SR in MOE preschools in Klang Valley, Malaysia. The objectives are to assess the quality of modified open-plan spaces and cognitive SR among MOE preschools in Klang Valley and to establish the degree of correlation between these two aspects.

\subsection{Study Design}

The basis for this study is the Piagetian approach to preschool design and cognitive development. Therefore, the assessment tools for the quality of modified open-plan spaces and cognitive SR should be based on this. The Children Physical Environment Rating Scale 5 (CPERS5) is a recognised appraisal tool developed specifically to assess PPE quality against the Piagetian approach, thus, is suitable for this study (Moore, 2012). Moreover, CPERS5 also measures the quality of modified open-plan spaces along with other aspects of preschool design, allowing us to conduct comparative studies. Likewise, the Bracken School Readiness Assessment (BSRA)-3 tool measures preschool children's cognitive readiness to enter primary school, thus was chosen to evaluate cognitive SR (Bracken, 2007).

In this study, MOE preschools were selected because they cater the broadest range of socio-demographic backgrounds compared to other public preschools and Klang Valley was chosen as the region with the most well-adjusted demographic distribution in Malaysia. Moreover, MOE preschools will be the main public preschool in Malaysia by 2025, hence, assessment of MOE preschools would further highlight the importance of this study (MOE, 2020). Further, purpose-built MOE preschools from the year 2002 that only cater to sixyears-old children were selected to ensure that participants were exposed to the same syllabus, teaching, and social environment throughout the study. Based on these criteria, $19 \mathrm{MOE}$ preschools were shortlisted, but 1 refused to participate, hence 18 were enrolled.

800 six-year-old MOE preschool children were registered in Klang Valley. A minimum of 363 children (20.17 per selected preschool) was needed to represent this population with $99 \%$ confidence. Thus, a total of 21 preschoolers were randomly selected from each preschool to standardise the number of participants per school, giving a final total of 378 children.

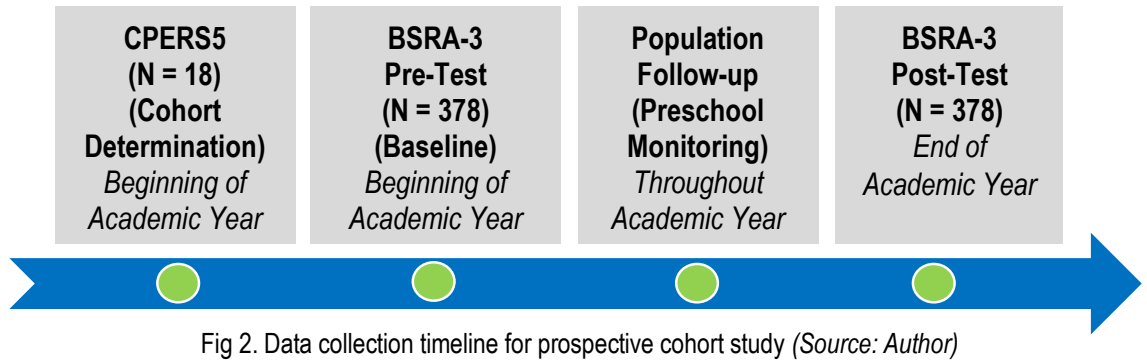

To investigate the relationship between the quality of modified open-plan spaces and children's cognitive SR, an observational prospective cohort study involving $18 \mathrm{MOE}$ preschools in Klang Valley and 378 six-year-old preschoolers was conducted (Figure 2). This permits us to prospectively observe changes among children in a temporal manner, with minimal interference on both the preschool and preschool children.

Adhering to cohort study designs, the study begins with a building survey using the CPERS5 assessment to define each cohort. Pertaining cognitive SR, the BSRA-3 tool is a scoring tool specifically designed for preschool-aged children. Based on the questions in BSRA-3, the researcher asks the child to point to specific objects in the BSRA-3 Booklet (i.e. a ball, a number etc.) whilst observing the child's ability to recognise these objects. No other form of responses from the child are required nor assessed. The child's ability to point to the correct object is then scored according to the BSRA-3 guidelines.

Cognitive SR of each preschooler at the beginning and end of the academic year were tmeasured with BSRA-3 Pre-Test and PostTest, respectively. This is done to measure the child's change in cognitive SR (dependent variable) whilst being exposed to the preschool physical environment (independent variable) - enabling us to establish the temporal impact of the preschool on cognitive SR.

For correlation analysis, the BSRA-3 Final Score for each preschooler is obtained using this formula:

BSRA-3 Final Score = BSRA-3 Post-Test - BSRA-3 Pre-Test

All preschools were followed-up throughout the study (monthly) to ensure each cohort remained consistent. For this, a complete inventory of the preschool was done before the study and referred to during every follow-up session. Finally, Pearson's correlation analysis was conducted to look at the strength of association between all CPERS5 subscales and cognitive SR (BSRA-3 Final Score).

\subsection{Variables}

The independent variables are the quality of modified open-plan spaces and other physical aspects of preschool design such as size, image and scale, circulation, shared facilities, indoor environment quality, safety, home bases, activity areas, and play yards. The dependent variable is the cognitive SR among the MOE preschoolers.

\subsection{Limitations}

This study was only limited to the selected MOE preschools. Thus, it could not be generalised to other preschool types. Only 6-year-old children were recruited thus the study cannot represent other age groups. The study was also conducted in Klang Valley due to the balanced socio-demographic distribution. Thus, it cannot represent MOE preschools in other localities in Malaysia. 


\subsection{Data Analysis}

Descriptive analyses were done on CPERS5 data and subscale means were categorised according to CPERS5 guidelines (Poor, Fair, Good, and Excellent). Normality tests (Shapiro-Wilk, Z-Skewness \& Z-Kurtosis), reliability test (Cronbach's a), and significance T-test (2-tailed) were done on all CPERS5 and BSRA-3 data. Pearson correlation analysis was conducted to determine the relationship between all aspects of CPERS5 and BSRA-3 Final Score. All statistical analyses done using SPSS (25).

\subsection{Findings}

\subsection{Descriptive and Reliability of CPERS5 and BSRA-3 Final Scores}

Table 1. Descriptive Analysis of CPERS5 (Subscales 1 - 14) and BSRA-3 Final Scores

\begin{tabular}{lllllll}
\hline Item & $\mathrm{N}$ & Min. & Max. & Mean & SD & Rating \\
\hline CPERS5 Subscale 1 (Centre Size \& Modules) & 18 & 0.250 & 2.670 & 1.376 & 0.688 & Fair \\
CPERS5 Subscale 2 (Image \& Scale) & 18 & 2.165 & 3.050 & 2.420 & 0.280 & Good \\
CPERS5 Subscale 3 (Circulation) & 18 & 0.500 & 2.830 & 2.007 & 0.717 & Good \\
CPERS5 Subscale 4 (Common Shared Facilities) & 18 & 1.180 & 2.000 & 1.501 & 0.255 & Fair \\
CPERS5 Subscale 5 (Indoor Environment Quality) & 18 & 1.575 & 2.570 & 2.000 & 0.351 & Fair \\
CPERS5 Subscale 6 (Safety \& Security) & 18 & 1.250 & 3.050 & 2.310 & 0.550 & Good \\
CPERS5 Subscale 7 (Modified Open-Plan Spaces) & 18 & 0.500 & 3.000 & 1.938 & 0.729 & Fair \\
CPERS5 Subscale 8 (Home Base) & 18 & 2.165 & 2.670 & 2.420 & 0.152 & Good \\
CPERS5 Subscale 9 (Quiet Activity Areas) & 18 & 0.500 & 3.000 & 1.709 & 0.700 & Fair \\
CPERS5 Subscale 10 (Physical Activity Areas) & 18 & 0.000 & 1.800 & 0.815 & 0.495 & Poor \\
CPERS5 Subscale 11 (Messy Activity Areas) & 18 & 0.650 & 1.600 & 0.964 & 0.290 & Poor \\
CPERS5 Subscale 12 (Play Yards - Functional) & 18 & 1.570 & 3.150 & 2.325 & 0.423 & Good \\
CPERS5 Subscale 13 (Play Yards - Developmental) & 18 & 0.385 & 2.255 & 1.215 & 0.454 & Fair \\
CPERS5 Subscale 14 (Location \& Site) & 18 & 2.275 & 3.360 & 2.890 & 0.368 & Good \\
BSRA-3 Final Score & 378 & -20 & 55 & 9.670 & 14.23 & Fairly Ready \\
\hline
\end{tabular}

${ }^{*}$ CPERS5 score rating: - Poor $(0.000-1.000)$, Fair $(1.001-2.000)$, Good $(2.001-3.000)$, Excellent $(3.001-4.000)$ (Source: Author)

Table 2. Normality of CPERS5 (Subscales $1-14$ ) and BSRA-3 Final Scores

\begin{tabular}{llllll}
\hline Item & $\mathrm{N}$ & Shapiro-Wilk sig. $(\mathrm{p})$ & Z-Skewness & Z-Kurtosis & Normal \\
\hline CPERS5 Subscale 1 (Centre Size \& Modules) & 18 & 0.103 & -0.202 & -1.077 & Yes \\
CPERS5 Subscale 2 (Image \& Scale) & 18 & 0.177 & 0.789 & -0.646 & Yes \\
CPERS5 Subscale 3 (Circulation) & 18 & 0.709 & -0.884 & 0.444 & Yes \\
CPERS5 Subscale 4 (Common Shared Facilities) & 18 & 0.209 & 1.336 & -0.232 & Yes \\
CPERS5 Subscale 5 (Indoor Environment Quality) & 18 & 0.199 & 0.307 & -0.905 & Yes \\
CPERS5 Subscale 6 (Safety \& Security) & 18 & 0.155 & -0.659 & -0.772 & Yes \\
CPERS5 Subscale 7 (Modified Open-Plan Spaces) & 18 & 0.128 & -0.739 & -1.338 & Yes \\
CPERS5 Subscale 8 (Home Base) & 18 & 0.069 & 0.099 & -0.661 & Yes \\
CPERS5 Subscale 9 (Quiet Activity Areas) & 18 & 0.100 & 1.609 & 0.331 & Yes \\
CPERS5 Subscale 10 (Physical Activity Areas) & 18 & 0.464 & 0.605 & -0.351 & Yes \\
CPERS5 Subscale 11 (Messy Activity Areas) & 18 & 0.159 & 1.053 & 0.656 & Yes \\
CPERS5 Subscale 12 (Play Yards - Functional) & 18 & 0.688 & 0.449 & 0.114 & Yes \\
CPERS5 Subscale 13 (Play Yards - Developmental) & 18 & 0.773 & 0.559 & 0.567 & Yes \\
CPERS5 Subscale 14 (Location \& Site) & 18 & 0.156 & -0.437 & -1.063 & Yes \\
BSRA-3 Final Score & 378 & 0.099 & -0.151 & -0.149 & Yes \\
\hline
\end{tabular}

*Normal distribution if Shapiro-Wilk (p) $>0.05,-0.863<$ Z-Skewness $<1.700$, and $-1.263<$ Z-Kurtosis $<0.896$ (Source: Author)

Table 3. Reliability of CPERS5 (Subscales $1-14)$ Scores $(\mathrm{N}=18)$

\begin{tabular}{lll}
\hline Item & $\begin{array}{c}\text { Cronbach's a } \\
\text { If Item Deleted }\end{array}$ & Cronbach's a \\
\hline CPERS5 Subscale 1 (Centre Size \& Modules) & 0.801 & 0.833 \\
CPERS5 Subscale 2 (Image \& Scale) & 0.702 & \\
CPERS5 Subscale 3 (Circulation) & 0.706 & \\
CPERS5 Subscale 4 (Common Shared Facilities) & 0.780 & \\
CPERS5 Subscale 5 (Indoor Environment Quality) & 0.708 & \\
CPERS5 Subscale 6 (Safety \& Security) & 0.761 & \\
CPERS5 Subscale 7 (Modified Open-Plan Spaces) & 0.743 & \\
CPERS5 Subscale 8 (Home Base) & 0.716 & \\
CPERS5 Subscale 9 (Quiet Activity Areas) & 0.715 & \\
CPERS5 Subscale 10 (Physical Activity Areas) & 0.762 & \\
CPERS5 Subscale 11 (Messy Activity Areas) & 0.812 & \\
CPERS5 Subscale 12 (Play Yards - Functional) & 0.816 & \\
CPERS5 Subscale 13 (Play Yards - Developmental) & 0.799 & \\
CPERS5 Subscale 14 (Location \& Site) & 0.746 & \\
CPERS5 Total Score & 0.701 & \\
\hline
\end{tabular}

*Reliable if Cronbach's a if item deleted < Cronbach's a and > 0.7 (Source: Author)
Table 4. Reliability of BSRA-3 Final Scores $(\mathrm{N}=378)$

\begin{tabular}{lll}
\hline Item & $\begin{array}{l}\text { Cronbach's a } \\
\text { If Item Deleted }\end{array}$ & Cronbach's a \\
\hline BSRA-3 Subtest 1 & 0.701 & 0.790 \\
BSRA-3 Subtest 2 & 0.702 & \\
BSRA-3 Subtest 3 & 0.751 & \\
BSRA-3 Subtest 4 & 0.709 & \\
BSRA-3 Subtest 5 & 0.735 & \\
BSRA-3 Total Score & 0.764 & \\
\hline
\end{tabular}

(Source: Author) 
From Table 1, MOE preschools did not achieve 'Excellent' rating for any PPE aspect. For BSRA-3 Final Score, MOE preschoolers were only found to be 'Fairly Ready' in terms of cognitive SR. Based on BSRA-3 assessment procedures, preschool children should be at least 'Very Ready' to ensure a seamless transition into primary school (Bracken, 2007). This shows that MOE preschool children are not cognitive SR for school. Table 2 shows results of normality assessments for all data. Shapiro-Wilk, Z-kurtosis, and Z-Skewness values were all within normal ranges, hence data is considered normally distributed (Field, 2017).

The reliability assessment of CPERS5 shown in Table 3 exhibited Cronbach's Alpha (a) of 0.833 . Cronbach's Alpha (a) for each subscale ranged between 0.701 and 0.816 - indicating data are reliable. Similarly, BSRA-3 Final Score exhibited Cronbach's Alpha (a) of 0.790 , with Cronbach's Alpha (a) for each subtest ranging between 0.701 and 0.764 , which is lower than 0.790 (Table 4). This indicates that the collected CPERS5 and BSRA-3 data are highly reliable (Field, 2017).

\subsection{Pearson's Correlation Analysis of CPERS5 and BSRA-3 Final Scores}

Table 5. Correlation between CPERS5 (Subscales $1-14)$ and BSRA-3 Final Score $(\mathrm{N}=378)$

\begin{tabular}{|c|c|c|c|}
\hline \multirow[t]{2}{*}{ Item } & \multicolumn{2}{|c|}{ BSRA-3 Final Score } & \multirow[t]{2}{*}{ Strength of Correlation } \\
\hline & Pearson's r-coefficient & Sig. 2-tailed $(p)$ & \\
\hline CPERS5 Subscale 1 (Centre Size \& Modules) & 0.425 & 0.000 & Moderate \\
\hline CPERS5 Subscale 2 (Image \& Scale) & -0.050 & 0.337 & mocia \\
\hline CPERS5 Subscale 3 (Circulation) & 0.474 & 0.000 & Moderate \\
\hline CPERS5 Subscale 4 (Common Shared Facilities) & 0.268 & 0.000 & Weak \\
\hline CPERS5 Subscale 5 (Indoor Environment Quality) & 0.219 & 0.001 & Weak \\
\hline CPERS5 Subscale 6 (Safety \& Security) & 0.210 & 0.001 & Weak \\
\hline CPERS5 Subscale 7 (Modified Open-Plan Spaces) & 0.658 & 0.000 & Moderate \\
\hline CPERS5 Subscale 8 (Home Base) & 0.030 & 0.558 & - \\
\hline CPERS5 Subscale 9 (Quiet Activity Areas) & 0.416 & 0.000 & Moderate \\
\hline CPERS5 Subscale 10 (Physical Activity Areas) & 0.219 & 0.001 & Weak \\
\hline CPERS5 Subscale 11 (Messy Activity Areas) & 0.309 & 0.000 & Weak \\
\hline CPERS5 Subscale 12 (Play Yards - Functional) & 0.045 & 0.378 & - \\
\hline CPERS5 Subscale 13 (Play Yards - Developmental) & -0.088 & 0.089 & - \\
\hline CPERS5 Subscale 14 (Location \& Site) & 0.054 & 0.294 & - \\
\hline
\end{tabular}

*Strength of correlation, $r<0.2=$ no correlation, $r>0.2=$ weak, $r>0.4=$ moderate, $r>0.7=$ strong (Source: Author)

Table 5 shows the Pearson's correlation for CPERS5 subscales and BSRA-3 Final Scores. Expectedly, in Table 5 we see that not all PPE aspects were associated with BSRA-3 Final Score. The Strength of correlation was determined using Guildford's Rule of Thumb ( $r>0.2=$ weak, $r>0.4=$ moderate, $r>0.7=$ strong) (Field, 2017) and are discussed in subsection 5.2. The quality of modified openplan spaces demonstrated the highest correlation with cognitive $S R(r=0.658, p=0.000)$, confirming our hypothesis that modified openplan spaces play an integral role in cognitive SR among Malaysian MOE preschools.

\subsection{Scatter Plot of Items with Strongest Correlation (Moderate)}

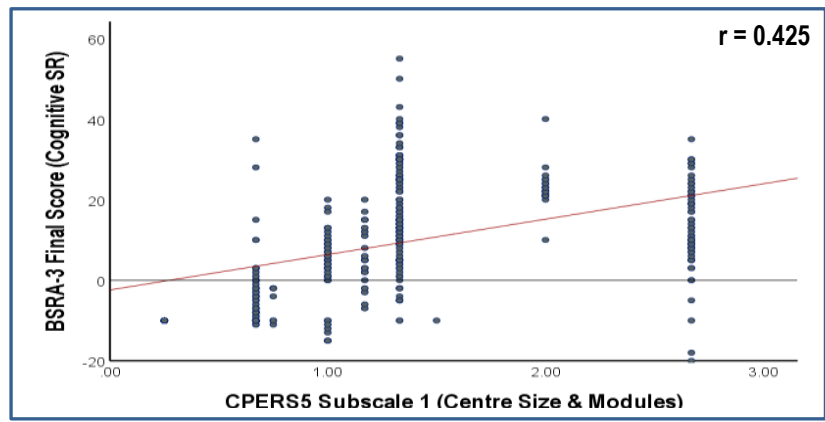

Fig 3. CPERS5 Subscale 1 (Centre Size \& Modules) \& BSRA-3 Final Score $(N=378)$ (Source: Author)

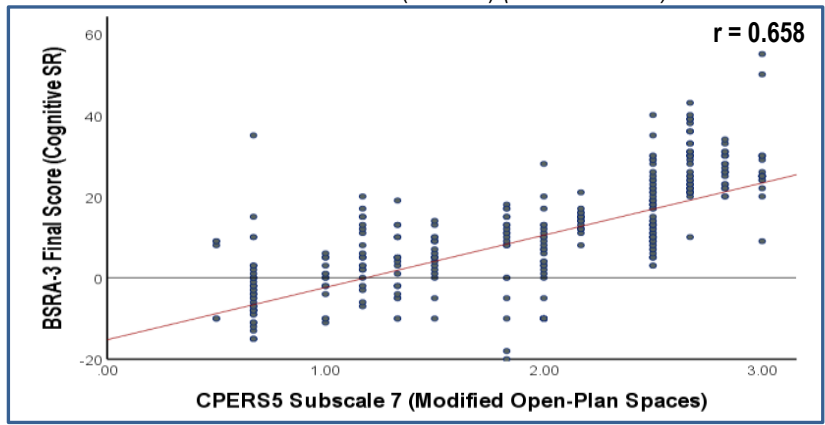

Fig 5. CPERS5 Subscale 7 (Modified Open-Plan Spaces) \& BSRA-3 Final Score $(\mathrm{N}=378)$ (Source: Author)

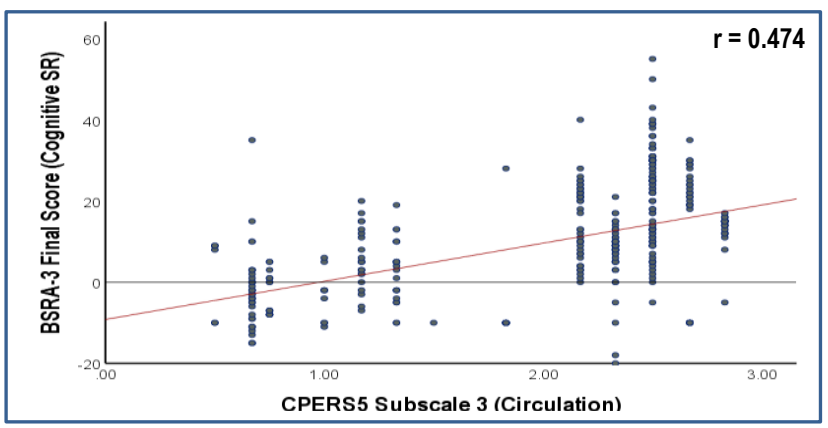

Fig 4. CPERS5 Subscale 3 (Circulation) \& BSRA-3 Final Score $(\mathrm{N}=378)$ (Source: Author)

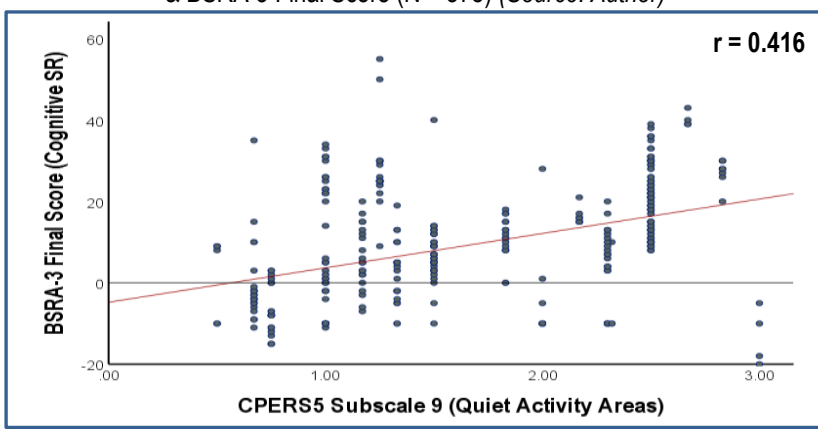

Fig 6. CPERS5 Subscale 9 (Quiet Activity Areas) \& BSRA-3 Final Score $(\mathrm{N}=378)$ (Source: Author) 


\subsection{Discussion}

\subsection{Descriptive Analysis of CPERS5 and BSRA-3 Final Scores}

Being the main aspect for learning activities, the quality of activity spaces (quiet, physical, messy) among MOE preschools is worrying. None were 'Good' nor 'Excellent'. Since pretend and explorative play constitutes a significant portion of children's learning, the fact that physical and messy activity areas were 'Poor' is detrimental to their learning and development in preschools (Mickelson, 2019). This is unsurprising as crucial aspects that impact spatial design namely size and planning (modified open-plan spaces) were only 'Fair'. This agrees with findings made in previous studies (Moore, 2012) and underscores the importance of preschool size and modified open-plan spaces to ensure ample space and conducive learning spaces, respectively.

As for PPE aspects rated 'Good', we can deduce that image, safety and security, and site location indeed benefitted from MOE preschools being annexed within primary school compounds. This is commendable and should be advocated for other public preschool designs. Being within primary school compounds enable MOE preschools to share or take advantage of amenities and features that are available in much more established institutions namely security and safety, whereby preschool buildings are often within the line of sight of other working adults during school time. Moreover, in terms of location, MOE preschools are often located in desired areas far away from hazardous elements such as traffic and high-tension power cables. Nonetheless, these preliminary findings confirm our concern that Malaysian public preschools are lacking in most aspects of PPE design. More improvements are needed to ensure better quality across all aspects of the preschool building.

\subsection{Strength of Correlation Between PPE Aspects with Cognitive SR}

As different PPE aspects are intended for different purposes, we anticipate varying correlation strengths between CPERS5 subscales and BSRA-3 Final Score (Shaari et al., 2020b). Subscales 4 (Common Shared Facilities), 5 (Indoor Environment Quality), 6 (Safety \& Security), 10 (Physical Activity Areas), and 11 (Messy Activity Areas) demonstrated weak correlation with BSRA-3 Final Score. This suggests these aspects do not affect cognitive SR directly, but rather, indirectly - perhaps in combination with one another. For example, aspects such as common shared facilities, indoor environment quality, and safety mainly function to provide comfort for both teachers and students but do not influence learning processes directly. Hence, they are only weakly correlated with cognitive SR, as in Table 5 . Moreover, physical and messy activity areas accommodate physical as well as art and craft activities. Explaining why they are also only weakly associated with cognitive SR.

Conversely, quiet activity areas (subscale 9) showed a moderate correlation with cognitive SR. Since this activity area is mainly intended for reading and learning, it should be more correlated with cognitive development, as seen from our data - corroborating Moore (2012). Moreover, other important aspects of preschool design namely size (Subscale 1), circulation (Subscale 3), and modified openplan spaces (Subscale 7) were moderately associated with cognitive SR. Given the importance of size, modified open-planning and quality of circulation in indoor preschool spaces in creating a conducive learning environment for preschoolers, these aspects are expected to impact children's cognitive SR more strongly.

Although MOE preschools mostly adopt open-planned spaces which would result in better circulation, the poorer quality of modified open-plan spaces (due to a large and open central space), the adoption of some elements of modified open-plan spaces (Figure 1) benefited from this to a certain extent, albeit not as much as expected because modified open-plan spaces (Subscale 7) was only rated Fair (Table 1). From the preschool child's perspective, there should be a balance between designing appropriate circulation and spatial planning in preschool environments as they can result in spaces being too big and overwhelming.

\subsection{Modified Open-Plan Spaces Showed Strongest Correlation with Cognitive SR}

To visualise the data, correlation scatter plots were illustrated (Subsection 4.3). As shown, we see that modified open-plan spaces (Figure 5) demonstrated the best goodness-of-fit line (marked red) compared to other aspects (Figures 3, 4 and 6). This further supports our proposition on the strength of correlation with cognitive SR, compared to other aspects of the PPE.

From the scatter plots we can deduce that for modified open-plan spaces, when scores are above 2.00 (Good \& Excellent), no negative BSRA-3 Final Score data were seen, meaning no reduction in cognitive SR was observed. This means, when the quality of modified open-plan spaces was Good, an improvement in cognitive SR was seen in all assessed preschool children. This is not seen in other aspects, as shown in Figures 3,4 , and 5 . This is significant as it suggests the importance of adopting high quality modified openplan spaces in preschools. The existence of preschools with 'Excellent' rating for modified open-plan spaces would enable us to further argue this. There are several reasons why modified open-plan spaces demonstrated the strongest correlation with children's cognitive SR. As spatial planning is crucial for the correct allocation of space for daily learning activities, the quality of modified open-planned spaces thus directly influences the preschool's capacity to accommodate its main purpose - to ensure cognitive development and subsequent cognitive SR.

Moreover, spatial planning is also important for the correct design of other secondary preschool spaces such as common shared facilities and home bases which do not affect cognitive SR directly but do so indirectly. For example, preschoolers feel more at home if home bases and shared facilities are ample and thus affects their motivation to learn, indirectly impacting their grasp of cognitive abilities thought in school (Moore, 2012). Interestingly, as Mealings and colleagues (2015) reported, spatial planning greatly impacts children speech perception in preschool learning, thus affecting their cognitive development, further validating our proposition.

Taken together, this highlights the importance of modified open-plan spaces in the preschool design. Without appropriate planning of spaces that are crucial for learning, preschool education cannot be maximised and could be detrimental to children's cognitive development (Dayaratne, 2016). 


\subsection{Conclusion \& Recommendations}

Findings show that among all PPE design elements, modified open-plan spaces demonstrated the strongest correlation with cognitive SR among Malaysian MOE preschools. Given the quality of modified open-plan spaces were only found to be 'Fair', more emphasis should be given on the appropriateness of spatial planning in preschools to accommodate children's learning behaviour. As it was also found that Malaysian preschoolers were only fairly ready for primary school, there is an urgent need for more attention to be given on the quality of spatial planning as it would greatly impact the quality of activity spaces and subsequent cognitive SR. The current status of PPE design quality of MOE preschools explains why Malaysia's public preschool initiatives under MEB 2025 were inadequate to improve Malaysia's PISA rankings. With the benefits modified open-plan spaces have to offer in maximising positive stimuli to encourage children learning, designers should tailor their ideas to incorporate more cosy 'pockets of activity spaces' within preschool classrooms. More appropriate partitioning could also be placed to further define open planned spaces and protect children from distractions, as suggested by Mealings and co-workers (2015). Taking the child's perspective into account, such a shift in design principle could go a long way to ensure Malaysian children are afforded better cognitive development as they progress in life. Ultimately, it is hoped that the quality of PPE design in Malaysian preschools does not continue to be overlooked and that this study could help to elicit more awareness on the importance of modified open-planning in childhood education to ensure more conducive preschool environments.

\section{Acknowledgements}

We thank Professor Moore for the use of CPERS5 and the Ministry of Higher Education of Malaysia for the Fundamental Research Grant Scheme (FRGS), reference: 600-RMI/FRGS 5/3 (113/2015)

\section{Paper Contribution to Related Field of Study}

This study furthers the understanding of the impact of spatial planning, particularly modified open-plan spaces, on cognitive SR of preschool children in MOE preschools in Malaysia in an effort to ensure better education for the future generation in Malaysia.

\section{References}

Abbas, M. Y., Othman, M., \& Rahman, P. Z. M. A. (2016). Pre-School Children's Play Behaviour Influenced by Classroom's Spatial Definitions? Asian Journal of Environment-Behaviour Studies, 1(1), 49-65.

Blair, C., \& Raver, C. C. (2015). School Readiness \& Self-Regulation: A Developmental Psychobiological Approach. Annual Review of Psychology, (66), 711-731.

Bracken, B., A. (2007). BSRA-3 Examiner's Manual.Pearson, San Antonio.

Davies, N., Cooper, R., \& Bains, M. (2020). What is school readiness? A qualitative exploration of parental perceptions in England. Journal of Health Visiting, 338-344.

Dayaratne, R. (2016). Creating Places Through Architecture: Can Environment-Behaviour Help? Asian Journal of Behavioural Studies, 1(2), 1-12.

Field. A. (2017). Discovering Statistics Using IMB SPSS Statistics. $5^{\text {th }}$ Edition. SAGE Publications Ltd.

Mealings, K. T., Demuth, K., Buchholz, J. M., \& Dillon, H. (2015). The effect of different open plan and enclosed classroom acoustic conditions on speech perception in Kindergarten children. The Journal of the Acoustical Society of America, 138(4), 2458-2469.

Mickelson, E. L. (2019). The Effects of Play-Based Learning on Behavior and Academic Progress in the Kindergarten Classroom (Doctoral dissertation, Baker University).

Ministry of Education (MOE). (2020). Malaysia Education Blueprint 2013-2025 (Preschool to Post-Secondary Education). Retrieved from https://www.moe.gov.my/images/dasar-kpm/articlefile_file_003108.pdf

Moore, G. T. (2012). Update on The Children's Physical Environments Rating Scale (CPERS5). Children Youth and Environments, 22(2), 311-312.

Mohidin, H. H. B., Ismail, A. S., \& Ramli, H. B. (2015). Effectiveness of Kindergarten Design in Malaysia. Procedia-Social and Behavioral Sciences, $202,47-57$.

Organisation for Economic Cooperation and Development (OECD), (2018). Retrieved from http://www.oecd.org/pisa/test.

Oseland, N. (2018). Open Plan Classrooms, Noise \& Teacher Personality. Retrieved from http://www.acousticbulletin.com/wp-content/uploads/2019/01/open-planteacher-personality-v3-4.pdf

Raghubar, K. P. \& Barnes, M. (2017). Early Numeracy Skills in Preschool-Aged Children: A Review of Neurocognitive Findings and Implications for Assessment. Clin Neuropsychol., 31(2), 329-351.

Schultz, D. P., \& Schultz, S. E. (2016). A History of Modern Psychology. Cengage Learning, Nelson Education, Ltd., Boston. 
Shaari, M.F., et.al., AIVCE-BS-2, 2020ShahAlam, cE-BS, FSPU, Universiti Teknologi MARA, Shah Alam, Malaysia, 02-03 Dec 2020, E-BPJ, 5(15), Dec 2020 (pp.123-130)

Shaari, M. F., Ahmad, S. S., Ismail, I. S., \& Zaiki, Y. (2020a). Preschool Physical Environment Design Quality: Addressing Malaysia's PISA Rankings. Asian Journal of Environment-Behaviour Studies, 5(16), 45-57.

Shaari, M. F., Ahmad, S. S., Ismail, I. S., \& Zaiki, Y. (2020b). Addressing Recent PISA Rankings: The potential role of preschool physical environment design quality in Malaysia. Environment-Behaviour Proceedings Journal, 5(13), 93-99. 